\title{
CONTRIBUIÇÕES DA FORMAÇÃO CONTINUADA PARA PROFESSORES UNIVERSITÁRIOS INGRESSANTES
}

\author{
CONTINUING EDUCATION CONTRIBUTIONS TO UNIVERSITY PROFESSORS INGRESS
}

CONTRIBUCIONES DE LA FORMACIÓN CONTINUADA DE PROFESORES UNIVERSITARIOS INGRESOS

\author{
NASCIMENTO, Priscila Ximenes Souza do 1 \\ ROMANOWSKI, Joana Paulin²
}

\section{RESUMO}

Este artigo analisa a formação continuada percebida por professores universitários em seu processo de inserção profissional na perspectiva das contribuições dessa formação para o aprendizado e a superação das dificuldades da docência. As referências envolvem: Vaillant; Marcelo (2012), Romanowski (2007), Marcelo García (1999, 2010), Day (2001) e Zanchet et al. (2014). A metodologia consistiu em abordagem qualitativa com coleta de dados por meio de questionário respondido por 15 (quinze) professores iniciantes. Foi possível inferir que a formação continuada contribui numa perspectiva de instrumentalização docente. Palavras-chave: Formação continuada de professores. Inserção profissional docente. Docência no ensino superior.

\section{ABSTRACT}

This article analyze the continuing education perceived by university professors in the process of professional insertion in the perspective of the contributions of this training to the learning and overcoming the difficulties of teaching. References include: Vaillant; Marcelo (2012), Romanowski (2007), Marcelo García (1999, 2010), Day (2001) and Zanchet et al. (2014). The methodology was based on qualitative approach with data collection through a questionnaire answered by 15 (fifteen) beginning teachers. It was possible to infer that continuing education contributes in a perspective of teaching instrumentation.

Keywords: Continuing education of teachers. Professional teacher insertion. Teaching in higher education.

\section{RESUMEN}

Este artículo analiza la formación continuada percibida por profesores universitarios en lo proceso de inserción profesional en la perspectiva de las contribuciones de esa formación para el aprendizaje y superación de las dificultades de la docencia. Las referencias implican: Vaillant; Marcelo (2012), Romanowski (2007), Marcelo García (1999, 2010), Day (2001) y Zanchet et al. (2014). La metodología se basó en abordaje cualitativo con recolección de datos por medio de cuestionario respondido por 15 (quince) profesores principiantes. Fue posible inferir que la formación continuada contribuye en una perspectiva de instrumentalización docente.

Palabras clave: Formación continuada de profesores. Inserción profesional docente. Docencia en la enseñanza superior.

\footnotetext{
1 Pontifícia Universidade Católica do Paraná - PUCPR - Paraná - Brasil

2 Pontifícia Universidade Católica do Paraná - PUCPR - Paraná - Brasil
} 


\section{INTRODUÇÃO}

O presente artigo é resultado de um estudo sobre a formação continuada de professores universitários em processo de inserção profissional docente. Pesquisadores da docência universitária tais como Cunha (2007, 2014, 2016, 2018), Isaia, Bolzan e Giordini (2007), Morosini (2001), Pimenta e Almeida (2011), Pimenta e Anastasiou (2014), Veiga (2006, 2016), entre outros, têm afirmado que o exercício profissional da docência requer, além da formação na área do bacharelado, uma formação pedagógica. Esta se faz necessária, principalmente, para os professores iniciantes na docência, pois a maioria deles advém de uma atuação profissional em áreas específicas.

A formação para a docência é um elemento que pode suprir a falta de formação pedagógica que marca o processo de ingresso de professores no ensino superior. Pesquisas como a de Zanchet et al. (2014) demonstram que há, de fato, benefícios da formação contínua para o início das atividades docentes dos professores universitários. Entretanto, é possível que tais contribuições sejam apreendidas de maneiras diversas, estendendo-se, até mesmo, para além do previsto pelos responsáveis por essa formação. $A$ isso se acrescenta que a formação continuada se expressa complexa ao ser colocada como contribuição aos professores na compreensão pedagógica do ensino superior (BAPTAGLIN; ROSSETO; BOLZAN, 2014).

Ao abordar a formação dos professores da educação superior, é fundamental refletir sobre as principais finalidades desta educação na formação e no desenvolvimento de profissionais capazes de atuar no mundo do trabalho, de maneira cidadã e crítica, e de conhecer os problemas do mundo presente. Às finalidades se soma a promoção da cultura, da reflexão, da pesquisa e da investigação científica, com vistas ao desenvolvimento da ciência e da tecnologia, bem como a preservação de formas de democracia participativa. Está claro, portanto, que a docência superior não se restringe ao ensino de conteúdos disciplinares, como destacam Morosini (2001) e Cunha (2014).

Com base em tais considerações preliminares, a problemática do estudo focalizado neste artigo envolve o questionamento de como professores universitários percebem a formação continuada em seu processo de inserção na carreira docente universitária. Tendo em vista essa questão, definiuse como objetivo geral: analisar as contribuições percebidas por professores universitários em relação à formação continuada oferecida pela instituição de ensino superior (IES) na qual trabalham, em seu processo de inserção na carreira docente universitária. E, de maneira mais específica, estabeleceramse os seguintes objetivos: (i) caracterizar o processo de inserção na carreira docente universitária e (ii) discutir os propósitos da formação continuada de professores no ensino superior.

Com vistas a alcançar esses objetivos, a pesquisa que ensejou este trabalho consistiu em coleta de dados empíricos com a aplicação de um questionário on-line para professores do ensino superior. A análise dos dados foi desenvolvida segundo a abordagem de pesquisa qualitativa (GIBBS, 2009; LÜDKE; ANDRÉ, 2013) e foi tecido um diálogo entre o referencial teórico estudado e as informações concedidas pelos docentes por meio do referido questionário. $\mathrm{Na}$ análise dos dados, aplicou-se rigor nos processos de interpretação dos elementos estudados, tendo como norte as recomendações de Lüdke e André (2013) de não centralidade na produção de descrição de opiniões, 
mas no aprofundamento da compreensão de um fenômeno social em análises qualitativas. $\mathrm{O}$ cotejamento com referenciais teóricos foi fundamental para garantir esse rigor.

Responderam ao instrumento 26 (vinte e seis) docentes, entre os quais havia 15 (quinze) professores, cujo tempo de atuação no magistério superior varia de 6 (seis) meses a 5 (cinco) anos. Os consultados atuam em IES privadas, uma de caráter confessional no Paraná e outra particular em Pernambuco, e em IES públicas, sendo institutos federais e universidades federais e estaduais, do Paraná e de Pernambuco. Os professores convidados para participar da pesquisa, cerca de 50 (cinquenta), fazem parte da rede de contato das pesquisadoras decorrente das interações interinstitucionais do âmbito acadêmico. Os 15 (quinze) professores com atuação menor que 5 anos podem ser situados nos anos iniciais das fases de vida profissional de docentes do ensino superior, conforme postula Huberman (1992). As fases dos respondentes estão relacionadas à vida pessoal e profissional de entrada na carreira e de estabilização, retomadas no Brasil, por exemplo, em Isaia, Bolzan e Giordani (2007).

Nas duas primeiras seções deste artigo, é apresentado o aporte teórico que sustenta a reflexão aqui desenvolvida. A primeira trata sobre a inserção profissional docente e tem como referencial teórico os trabalhos de Day (2001), Lancey (1977), Marcelo García (1999, 2010), Vaillant e Marcelo (2012), e Zanchet et al. (2014). A segunda parte versa sobre a formação continuada de professores no ensino superior tendo respaldo em Pimenta e Anastasiou (2014), Romanowski (2007), Cunha (2007, 2014, 2018), Isaia, Bolzan e Giordani (2007), Morosini (2001), Pimenta e Almeida (2011), e Veiga (2016). Na terceira e na quarta seções deste escrito, são expostos os dados empíricos coletados e discutidos esses resultados a partir do referencial teórico apreciado nas seções antecedentes. Na última seção, são apresentadas as considerações finais.

\section{INSERÇÃO PROFISSIONAL NA DOCÊNCIA UNIVERSITÁRIA}

Os profissionais que ingressam na educação superior geralmente são professores jovens, iniciantes na profissão, dedicados à pesquisa, mas sem vivências na docência universitária, normalmente egressos de cursos de pós-graduação lato sensu ou mestres e doutores recentemente titulados (PIMENTA; ANASTASIOU, 2014). No entanto, 12 (doze) dos 15 (quinze) professores iniciantes respondentes deste estudo possuem formação para a docência, pois advêm de cursos de licenciatura, no qual cursaram disciplinas pedagógicas.

Conforme propõe Marcelo García (1999), a inserção profissional na docência é considerada uma das fases do desenvolvimento profissional dos professores, pois se trata de um período de formação específico em que ocorre a transição da condição de estudante para a de professor, mas que constitui uma continuidade no processo de aquisição de conhecimentos e atitudes sobre como se ensina. Portanto,

Falar da carreira docente não é mais do que reconhecer que os professores, do ponto de vista do "aprender a ensinar", passam por diferentes etapas (pré-formação, formação inicial, iniciação e formação permanente, de acordo com Feiman, 1983), as quais representam exigências pessoais, profissionais, organizacionais, contextuais, psicológicas, etc., específicas e diferenciadas. (MARCELO GARCÍA, 1999, p. 112). 
O processo de tornar-se professor ocorre de modo contínuo e, em certa medida, sistemático e organizado, mas dificilmente se dá de forma linear. Ao reconhecer na figura do professor sua condição de pessoa, e não apenas seu papel de empregado, é possível conceber seu desenvolvimento numa perspectiva menos centrada no aspecto administrativo, passando a considerar tanto a sua condição cognitiva e emocional quanto os contextos históricos e institucionais em que acontece o trabalho docente. Para Marcelo García (2010), a inserção na docência se caracteriza por um processo de aprender a ensinar, quer dizer, é uma fase em que o professor aprende a ensinar.

Essas considerações são colocadas por Day (2001), ao discutir os desafios da aprendizagem no desenvolvimento profissional dos professores. E ao discorrer sobre os estudos mais representativos a respeito desse tema, especialmente quanto às experiências na carreira e aos fatores que mais a influenciam, Day destaca o período da entrada na profissão. Para o autor, os professores iniciantes carregam consigo conceitos de ensino oriundos de suas experiências anteriores como estudantes. Ao ingressarem como docentes, enfrentam o duplo desafio de expressarem em seu trabalho esses conceitos e visões e de procurarem atender ao que as instituições solicitam. Com efeito, seu trabalho precisa corresponder "[...] à sua visão pessoal de como deveria ser, enquanto que, ao mesmo tempo, se encontram sujeitos às poderosas forças socializadoras da escola" (DAY, 2001, p. 102).

Nessa perspectiva, Lacey (1977) aponta as fases pelas quais os professores iniciantes passam: (i) "lua de mel”, (ii) "crise", (iii) "fracasso" ou “ir andando". A primeira, a fase de lua de mel, é o encantamento com a possibilidade de ser professor, estar em classe, tornar-se um profissional. A fase de crise acontece logo que o docente toma consciência de que está em classe e que tem a responsabilidade de ensinar. Quando nessa crise, o professor entra em processo agudo de dúvidas sobre si e suas possibilidades, podendo enfrentar receios intensos que gerem o abandono da docência. O autor assinala que qualquer uma dessas fases influencia o modo como o docente concebe o ensino, mas ressalta que é a capacidade do professor de lidar com a "crise" que será determinante na sua formação.

Essa ideia parece alinhar-se ao que Vaillant e Marcelo (2012, p. 123) afirmam com relação à inserção profissional na docência: "[...] os professores principiantes experimentam os problemas com maiores doses de incerteza e estresse, devido ao fato de que têm menores referências e mecanismos para enfrentar essas situações”. Dessa maneira, tais docentes necessitam de uma atenção específica das instituições educativas em que estão atuando no sentido de melhor auxiliá-los nesse período de tensões e aprendizagens, na redução ou recondução desse verdadeiro "choque com a realidade".

Entretanto, segundo Vaillant e Marcelo (2012), o que se verifica na realidade é que a inserção na docência é conduzida na maioria das vezes em situações assimétricas de "nadar ou fundir-se", em que os novos professores são responsabilizados individualmente por sua adequação à realidade e por sua inserção no contexto de trabalho. No âmbito universitário, a questão da inserção profissional docente apresenta-se de forma muito semelhante, contudo Zanchet et al. (2014, p. 188-189) salientam que o professor do ensino superior guarda peculiaridades, especialmente no que concerne à transição da condição de pesquisador para docente. Os autores afirmam que esses professores, quando assumem o magistério, 
[...] precisam processar a passagem entre uma formação que privilegia a pesquisa [para] uma prática significativamente exigente de docência. O professor, ao iniciar a carreira docente, é impactado por inúmeras exigências, precisando inserir-se na cultura do seu ambiente de trabalho e relacionar-se com seus colegas e alunos. Necessita, também, responder [a] questões burocráticas da ação docente bem como dos encaminhamentos de projeto de pesquisa, de ensino e de extensão, dentre outras tantas tarefas.

Zanchet et al. (2014) reforçam que conceber a indissociabilidade entre ensino, pesquisa e extensão parece ser um dos grandes desafios para o início da carreira desses professores, principalmente porque o contexto universitário que Ihes concedeu a titulação necessária para o trabalho docente (formação em nível de pós-graduação), em geral, oportunizou a vivência desses aspectos de forma fragmentada.

Soma-se a tal desafio o fato de grande parte desses professores, em sua formação inicial e até mesmo nos cursos de mestrado e/ou doutorado, terem construído conhecimentos centrados em sua área específica. Esse é um obstáculo, porque, no momento de iniciar a docência, é imprescindível a seu fazer profissional a elaboração de saberes pedagógicos mais consistentes do que aqueles de que conseguiram se apropriar ao longo da experiência como discentes. Assim, ao desenvolverem programas de formação continuada e de apoio que favoreçam a inserção desses novos professores no trabalho docente, as IES podem contribuir na compreensão da docência e no desenvolvimento profissional dos professores.

\section{FORMAÇÃO CONTINUADA DE PROFESSORES UNIVERSITÁRIOS}

No desenvolvimento profissional docente, o momento de inserção na profissão também pode se caracterizar como de formação, além de compor uma das fases que constituem o ser professor. Nessa fase há a possibilidade de interação entre pessoas adultas (formador-formando) num contexto relativamente organizado e de tempo delimitado, visando promover mudanças (MARCELO GARCÍA, 1999).

Em algumas instituições os docentes iniciantes vivenciam de forma solitária esse período de transição de estudantes/pesquisadores para professores, embora contem com momentos da chamada "formação em exercício" e "formação continuada" para compartilhar os erros, acertos, dilemas e conquistas com seus pares. Romanowski (2007) alerta que, durante os primeiros anos da docência, em que há um choque de realidade, os novos professores poderiam ser melhor assistidos pelos programas de formação continuada; no entanto, são, de modo geral, negligenciados pelas instituições formadoras e pelos sistemas de ensino. Sobre isso a autora esclarece:

O objeto da formação continuada é a melhoria do ensino, não apenas a do profissional. Portanto, os programas de formação continuada precisam incluir saberes científicos, críticos, didáticos, relacionais, saber-fazer pedagógico e de gestão [...]. Ressalta-se a necessária ênfase na prática dos professores com seus problemas como importante eixo condutor dessa modalidade de formação. [...]. Os programas de formação, ao possibilitarem conhecimentos sobre a escola e o sistema educativo e ao explicitarem a complexidade das situações de ensino e as possíveis alternativas de solução, a partir da prática, favorecem uma ação docente mais crítica e consciente. (ROMANOWSKI, 2007, p. 130-131). 
Além disso, estudos sobre iniciantes apontam que o processo de formação dos professores da educação superior ocorre de modo bastante similar aos dos professores da educação básica, no que se refere à constituição de saberes da docência (VAILLANT; MARCELO, 2012). Entretanto, Isaia, Bolzan e Giordani (2007, p. 2), ao discutirem sobre os ciclos de vida profissional de docentes do ensino superior, advertem que os cursos de licenciatura, ainda que incluam disciplinas pedagógicas, não abordam "atividade ou disciplina curricular que os preparasse[m] para atuar na Educação Superior". Alertam as autoras que essa falta de formação é mais intensa nos bacharelados, pois nesses cursos a formação pedagógica é inexistente.

A formação do professor da educação superior, ao considerar a prática docente, em que se elaboram e se efetivam saberes pedagógicos contextualizados, descortina a pedagogia universitária, como externam Cunha (2007) e Pimenta e Almeida (2011). Desse modo, essa pedagogia se configura para compreender o professor e o profissional bacharel, considerando dimensões amplas do contexto social. Cunha (2014, p. 457) alerta que a educação superior não se restringe ao ensino, ao ser composta pela tríade ensino, pesquisa e extensão, contudo o conceito de indissociabilidade é "pouco aprofundado no ambiente universitário".

Na educação superior, ao incidir sobre a práxis educativa, a formação se efetiva vinculada às intencionalidades sociais, da ciência e do trabalho; portanto, supera a neutralidade técnica. Nessa perspectiva, as instituições carecem de definir políticas de formação pedagógica de docentes universitários, considerando a diversidade de ações formativas, bem como de estimular e valorizar a produção científica dos docentes sobre o ensino e a interação com a sociedade, como propõem Pimenta e Almeida (2011).

Cabe registrar que a maioria dos professores universitários possui, por obrigatoriedade legal ${ }^{3}$, titulação em nível de pós-graduação e, atualmente, tanto nos cursos lato sensu como stricto sensu, via de regra, há uma disciplina dirigida à formação para a docência, o que confirma sua condição de iniciante no entendimento de Pimenta e Anastasiou (2014). Os egressos desses cursos de pósgraduação que receberam bolsa necessariamente realizaram estágio de docência. No caso dos professores participantes da pesquisa abordada neste artigo, a maioria, por ser oriunda de cursos de licenciatura, recebeu formação pedagógica acrescida de formação para a pesquisa. Essa formação, como destacado por Isaia, Bolzan e Giordani (2007), é mais direcionada para a educação básica, ainda que os fundamentos dos conhecimentos pedagógicos sejam indistintos quanto ao nível de ensino a que se destinam.

Pimenta e Anastasiou (2014) apontam a crescente preocupação desde meados da década de 1990 com a melhoria da qualidade dos resultados do ensino superior, o que proporcionou maior cuidado na preparação dos docentes desse nível de ensino no campo específico e pedagógico. Aliás, a exigência de mestrado e doutorado passou a incidir com maior rigor a partir da Lei de Diretrizes e Bases da Educação Nacional (BRASIL, 1996), como ressaltam as autoras ao explicitarem as diversas ações tomadas que provocaram importantes mudanças em todo o contexto educacional. Nesse

\footnotetext{
${ }^{3}$ Conforme o artigo 66 da Lei de Diretrizes e Bases da Educação Nacional - Lei N. ${ }^{\circ}$ 9.934, de 20 de dezembro de 1996 (BRASIL, 1996). O Censo de 2016 aponta que 40\% dos professores da educação superior são mestres, 38\% são doutores, somando $78 \%$ de professores titulados, conforme Romanowski e Mira (2018).
} 
sentido, alerta Cunha (2018) que a docência no ensino superior, no Brasil, historicamente é marcada pelo pensamento da ciência positivista, com ênfase na reprodução do conhecimento. As aulas são centralizadas "em repetições incansáveis, uma aprendizagem mecânica" (CUNHA, 2018, p. 8), concentram-se no modelo expositivo, no qual o aluno é orientado sobre o que estudar para posteriormente responder a questões em provas de avaliação. Mesmo com a inserção de tecnologias, a abordagem do ensino permanece "fundamentada na transmissão da informação". Há pouca discussão e debate na busca de novas perspectivas do conhecer e do aprender. Ressalta Cunha (2018, p. 9): "A sociedade está a requerer uma educação superior que se afaste das verdades prescritivas e enfrente a condição da incerteza e da mudança como um valor".

Portanto, diante de um panorama em que a formação no nível de pós-graduação e mesmo a formação em cursos de licenciatura são insuficientes para orientar a prática docente no ensino superior, iniciativas institucionais de formação continuada assumem um papel importantíssimo para os professores iniciantes na aquisição do conhecimento profissional, da cultura, dos rituais, dos símbolos e dos valores que fazem parte da docência universitária. Todavia, mais do que um conhecimento técnico do ofício, essa formação precisa considerar a complexidade da vida profissional e social que é permeada por situações incertas, conflitos diversificados e efeitos ambíguos, implicando na intensa e profunda inserção social, histórica e política das instituições na promoção da educação superior, acrescida da pesquisa e da extensão.

Diante desse quadro, os professores iniciantes, além das dificuldades de sua condição de ingresso, são desafiados a promover novas metodologias direcionadas para uma aprendizagem dos estudantes que contemple a elaboração e a compreensão do conhecimento em suas diferentes formas. A relação com as disciplinas sob sua responsabilidade assume perspectiva de desvelamento, ampliação de possibilidades, reflexões com as possíveis manifestações do saber numa perspectiva sócio-histórica da educação superior. Como afirma Cunha (2014, p. 461), trata-se de um "ensino em que o conhecimento é compreendido em construção e onde os estudantes atuam como protagonistas das aprendizagens, reconfigurando saberes, tempos e espaços de aprender", abrangendo uma educação para a cidadania. Assim, o professor da educação superior não se restringe a reproduzir os conhecimentos científicos, pois o exercício da docência envolve pesquisa e socialização de saberes, bem como formação sociopolítica dos estudantes.

\section{A FORMAÇÃO CONTINUADA NO INÍCIO DA CARREIRA DOCENTE: POSSIBILIDADES}

As tensões do início da carreira docente inegavelmente afetam a vida pessoal, profissional e social dos professores, quer seja no âmbito da educação básica, quer seja no do ensino superior. É fato que muitos desistem da docência por não conseguirem lidar com as crises dessa fase inicial da profissão e, mesmo que não tenham intenção de auxiliar os docentes iniciantes, os momentos de formação continuada podem servir como grande apoio nesse processo de tornar-se professor.

Nesta investigação, a intenção era observar as contribuições apontadas pelos professores respondentes sobre os momentos de formação no período de inserção profissional. Para coletar dados 
sobre esses apontamentos foi aplicado um questionário on-line $e^{4}$ com 8 (oito) perguntas, sendo as 6 (seis) primeiras direcionadas à identificação do perfil dos respondentes e as 2 (duas) últimas voltadas ao interesse de que falassem sobre os momentos de formação continuada de que participaram no início da carreira docente no ensino superior.

Responderam ao instrumento 26 (vinte e seis) docentes, dos quais 15 (quinze) informaram atuar no magistério superior por período que variava de 6 (seis) meses a 5 (cinco) anos, o que permitiu situá-los nos anos iniciais dos ciclos de vida profissional de docentes do ensino superior como indicado na introdução. Os demais respondentes informaram ter entre 5 (cinco) e 20 (vinte) anos de atuação docente universitária, o que os localiza na fase intermediária da carreira. O Gráfico 1 , a seguir, ilustra a distribuição do tempo de atuação profissional dos respondentes.

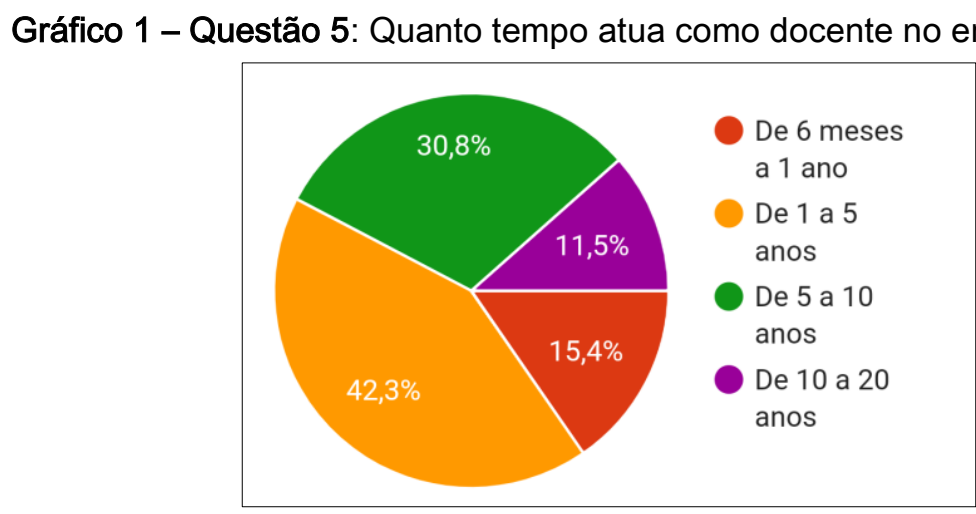

Fonte: As autoras (2018).

Ainda que menos da metade dos professores tenha um tempo superior a 5 (cinco) anos de docência, o instrumento de coleta de dados utilizado se referiu à formação continuada realizada quando estavam na condição de professores iniciantes, e informações significativas apontadas pelos professores desse grupo foram consideradas neste estudo.

Entre os 15 (quinze) professores iniciantes, apenas 3 (três) são do sexo masculino, 12 (doze) estão entre 20 e 39 anos de idade e 3 (três) estão na faixa etária de 40 a 59 anos. Entre os 11 (onze) docentes na fase intermediária, apenas 2 (dois) são do sexo masculino, 2 (dois) estão entre 20 e 39 anos de idade e 9 (nove) estão na faixa etária de 40 a 59 anos.

Quanto à formação, a maioria dos docentes iniciantes são formados em cursos de licenciatura (9 em Pedagogia, 2 em História e 1 em Química) e apenas 3 (três) possuem formação em cursos de bacharelado ( 1 em Ciências Contábeis, 1 em Psicologia e 1 em Gastronomia e Turismo). Os docentes da fase intermediária seguem semelhante proporção, sendo formados em Pedagogia (4), Filosofia (3), Teologia (1), Filosofia e Teologia (1), Engenharia Elétrica e Ciência da Computação (1) e Administração (1).

Quanto à formação em nível de pós-graduação, a maior titulação informada pelos docentes iniciantes foi de que 3 (três) são doutores (2 em Educação e 1 em área específica), 8 (oito) são mestres (6 em Educação e 2 em área específica) e 4 (quatro) são especialistas (2 na área educacional e 2 em

\footnotetext{
${ }^{4}$ Questionário disponível no apêndice, ao final deste artigo.
} 
área específica). Já entre os da fase intermediária, há 1 (uma) professora com pós-doutorado em Teologia, 5 (cinco) têm doutorado ( 2 em Educação e 3 em área específica) e 5 têm mestrado ( 3 em Educação e 2 em área específica). As instituições em que atuam - universidade confessional comunitária no Paraná, centro universitário particular em Pernambuco, Instituto Federal do Paraná e de Pernambuco e Universidade Federal e Estadual de Pernambuco - ofertam cursos de graduação em diferentes áreas, licenciaturas e bacharelados. Em algumas delas há cursos de pós-graduação em nível de especialização e de mestrado e doutorado. O contato das pesquisadoras com os docentes convidados para a pesquisa, por volta de 50 (cinquenta), ocorreu devido a atividades acadêmicas interinstitucionais em que se discutiam dilemas da formação e atuação do professor universitário.

Com isso, configura-se um quadro de respondentes em que a grande maioria realizou alguma formação para a docência. Dos 26 (vinte e seis) professores que responderam ao questionário, 20 (vinte) têm formação pedagógica em nível de graduação, e 15 (quinze), em nível de pós-graduação. Contudo, como alerta Cunha (2003), a pós-graduação stricto sensu valoriza mais a pesquisa do que o ensino durante o processo formativo de seus discentes, e isso pode, de certo modo, fragilizar a necessária reflexão teórico-prática que fundamenta a profissão docente.

No que se refere às instituições em que os respondentes disseram ter experiência docente, há, entre os professores iniciantes, 10 (dez) com experiência em IES privadas e 5 (cinco) em IES pública federal. Já entre os professores da fase intermediária, há 6 (seis) com experiência em IES privada, 2 (dois) em IES pública federal, 1 (um) em ambas, IES pública federal e privada, 1 (um) em IES pública federal, estadual e privada e 1 (um) professor que informou ter experiência em "Fundação", que pode ser considerada uma instituição de âmbito público, mas não gratuita.

Dentre os sujeitos dessa pesquisa, 8 (oito) dos 15 (quinze) professores iniciantes relataram ter participado de momentos de formação continuada oferecidos pela instituição de ensino em que trabalhavam quando do início de sua carreira como docente universitário, e o mesmo foi dito por 6 (seis) dos 11 (onze) professores da fase intermediária. Para os dois grupos, esses momentos tinham características diversificadas; na maioria das vezes, consistiam em palestras sobre aspectos teóricos e elementos burocráticos da instituição. As mesmas caraterísticas foram apontadas por 3 (três) dos outros 7 (sete) docentes iniciantes e por 2 (dois) dos outros 5 (cinco) professores da fase intermediária, mas que apontaram não ter participado desses momentos no início da carreira. Ao justificarem sua não participação, tais professores apontaram que teria pouco valor efetivo para a própria formação como docente universitário tomar parte dessas ocasiões em que foram realizadas as palestras pelas IES. Também se destaca o fato de boa parte desses 12 (doze) professores, mais exatamente 9 (nove), indicarem que (i) não houve a proposição de momentos de formação, (ii) eram destinados a professores efetivos, (iii) não havia carga horária disponível para participar e (iv) não se lembravam de ter havido oferta de formações no período em que ingressaram no magistério superior.

As respostas dos sujeitos da pesquisa indicam a pouca efetividade da formação continuada nas instituições de educação superior, quando esta ocorre sem vinculação com os problemas relacionados à prática docente e, em especial, com a formação dos estudantes, que são desconsiderados quando há foco no ensino (CUNHA, 2016). No que concerne ao desenvolvimento profissional dos professores, de modo geral, a formação se efetiva na perspectiva da ação docente, 
deixando, muitas vezes, de "fornecer respostas para as necessidades de seu desenvolvimento profissional" (ROMANOWSKI, 2007, p. 138).

A última pergunta do questionário solicitava o relato de 1 (uma) a 5 (cinco) contribuições da formação continuada oferecida pela universidade para o início de sua carreira como docente no ensino superior. As respostas dos participantes indicam 14 (quatorze) formas de contribuição percebidas pelos professores conforme apresentado no Quadro 1.

Quadro 1 - Pergunta 8: Contribuições da formação continuada

\begin{tabular}{|c|c|}
\hline $\begin{array}{l}\text { Contribuições da formação continuada } \\
\text { oferecida pela IES para o início da carreira como } \\
\text { docente no ensino superior: }\end{array}$ & $\begin{array}{l}\text { Quantidade de } \\
\text { professores que mencionaram } \\
\text { a contribuição: }\end{array}$ \\
\hline Estratégias metodológicas utilizadas nas & 4 \\
\hline Processo de avaliação da aprendizagem & 3 \\
\hline Aperfeiçoamento profissional/atualização & 3 \\
\hline Compartilhamento de práticas entre docentes & 3 \\
\hline $\begin{array}{l}\text { Possibilidade de repensar a prática } \\
\text { pedagógica }\end{array}$ & 3 \\
\hline $\begin{array}{l}\text { Melhor compreensão das características do } \\
\text { ensino superior }\end{array}$ & 3 \\
\hline Elaboração de plano de aula/de ensino & 2 \\
\hline Alinhamento com os princípios institucionais & 2 \\
\hline Uso de tecnologia/ferramentas virtuais & 2 \\
\hline Aperfeiçoamento pessoal & 1 \\
\hline $\begin{array}{l}\text { Aprendizagens sobre como lidar com } \\
\text { diferenças culturais }\end{array}$ & 1 \\
\hline Discussões acerca dos desafios do curso & 1 \\
\hline Revisão do Projeto Político-Pedagógico do & 1 \\
\hline Associação da prática à teoria & 1 \\
\hline
\end{tabular}

Fonte: As autoras (2018).

Ao examinar esse quadro, vê-se que a maioria das respostas aponta para uma formação direcionada para o aprendizado da docência. Destacam-se as contribuições mencionadas por mais de um professor que fazem referência ao trabalho docente em sala de aula, o que permite inferir uma preocupação comum dos programas de formação com a metodologia de ensino em aula, mas não com seus fundamentos. $\mathrm{O}$ foco são aspectos do saber fazer didático, com as ações diretamente ligadas à aprendizagem dos estudantes. As possíveis mudanças direcionam-se à inserção das tecnologias nas aulas, ou seja, um direcionamento de formação para a racionalidade técnica. Todavia, de acordo com 
Pimenta e Anastasiou (2014), é preciso considerar o atual contexto caracterizado por imprevisibilidade, singularidade, incerteza, novidade, dilema, conflito e instabilidade, não sendo mais o bastante aplicar somente uma racionalidade técnica.

Uma peculiaridade nesse painel de dados é o fato de grande parte dos professores respondentes terem formação para a docência desde a graduação, uma vez que realizaram cursos de licenciatura, mas ainda apontarem a necessidade de suporte quanto aos saberes pedagógicos. Como salientam Isaia, Bolzan e Giordani (2007), há uma formação nas licenciaturas direcionada à educação básica, cuja articulação com a educação superior não se transpõe de modo simples e direto.

Em pesquisa sobre professores iniciantes, Marcelo García (2010) reforça que a insegurança dos docentes é conduzida para o imediato da organização das aulas; daí o interesse dos professores por formações que os apoiem a decidir o que fazer. Desse modo, as formações focalizam o trato de técnicas de ensino. Nessa perspectiva, Veiga (2006) explicita que o foco no fazer restringe a formação, relegando a segundo plano a dimensão social, crítica e reflexiva da educação superior. Além disso, Veiga (2016) indica a compreensão do currículo como fundamental para o docente do ensino superior, dimensão pouco abordada na formação docente. Com efeito, Romanowski (2007) expressa que a formação pedagógica desarticulada da compreensão dos conhecimentos específicos distancia o ensino da prática profissional e dos problemas inerentes a ela, ou seja, resulta em um ensino centrado na transmissão de conteúdos.

Ao final do questionário, foi disponibilizado espaço para que os respondentes registrassem alguma informação adicional que considerassem importante. Apenas 6 (seis) dos investigados, sendo 3 (três) iniciantes e 3 (três) intermediários na carreira, fizeram esse comentário. Os professores iniciantes indicaram a busca de "capacitação" por conta própria, e um deles ressaltou o anseio de ter melhores oportunidades para atuar em IES públicas. Ao considerar a dimensão coletiva do processo de formação, ficou evidente algum grau de ressentimento no registro final de um desses docentes, pois este sinalizou que não acredita haver uma política de formação continuada para professores das IES e salientou que tal formação está submetida ao desejo e as possibilidades do próprio docente.

Entre os 3 (três) respondentes que estão na fase de experimentação/diversificação, um explicitou que as contribuições mais significativas para repensar sua prática pedagógica ocorreram há pouco tempo, provavelmente nos anos posteriores à fase de iniciação. O segundo docente registrou que lamentava não conseguir participar de mais encontros de formação e de oficinas em razão de demandas urgentes da universidade que Ihe tomam bastante tempo; o terceiro professor sinalizou que percebe uma crescente distância entre a formação continuada oferecida e a atividade docente e exemplifica a dificuldade das instituições em lidar com estudantes cada vez mais conectados à internet e interligados em rede. Esse professor acrescentou que vê apenas alguns docentes buscando, de modo intuitivo, enfrentar tais desafios.

O conteúdo das respostas associa a formação para a docência a elementos da organização didático-pedagógica como: (i) estratégias de ensino; (ii) processo de avaliação da aprendizagem; (iii) uso de tecnologia/ferramentas virtuais; (iv) elaboração de plano de aula. No entanto, embora os docentes valorizem esses aspectos, a formação permanece com foco acentuado na instrumentalização dos professores. Trata-se, portanto, de uma formação pautada mais no ensino a ser realizado pelo 
professor e menos na aprendizagem dos estudantes, como discutido por Marcelo García (2010). Mesmo nos demais itens indicados, apenas um se refere à possibilidade de repensar a prática pedagógica. Quanto ao compartilhamento de práticas, Cunha (2018) ressalta que essas trocas incidem no saber fazer, envolvendo explicações baseadas em senso comum, o que pouco contribui para reflexões sobre mudanças no fazer docente. Estudos constatam que a maior parte dos professores universitários não possuem uma formação específica para o ensinar; a despeito disso, ensinam e são bem-sucedidos, como apontam Veiga e Castanho (2000), Morosini (2001), Pimenta e Anastasiou (2014). Essas autoras destacam que o esforço de autoformação e o compartilhamento de experiências podem ajudar na realização do ensino e contribuir para a práxis docente.

Ainda, relatos dos docentes participantes da pesquisa apontam que as IES parecem estar mais preocupadas com questões de caráter burocrático, o que contradiz as considerações de Day (2001) sobre a concepção de desenvolvimento profissional como um continuum não linear, mais centrado na perspectiva de "professor como pessoa" do que na de "professor como empregado". Na esteira desse pensamento, Zanchet et al. (2014, p. 210) defendem a implementação de uma política global da universidade no que se refere tanto à formação pedagógica quanto ao desenvolvimento profissional dos professores universitários que "[...] dignifique e valorize as funções docentes como fundamentais para alcançar-se a excelência". Assim, conforme sinalizam Vaillant e Marcelo (2012), seria muito frutífero se as instituições de ensino apresentassem as condições necessárias para que os professores aprendessem continuamente e, assim, elas pudessem melhorar em sua condição de organizações educativas.

\section{CONSIDERAÇÕES FINAIS}

Atualmente, a profissão docente está fortemente caracterizada pela imprevisibilidade, singularidade, incerteza, novidade, dilema, conflito e instabilidade. No âmbito universitário, essa realidade exige o enfrentamento da lógica de formação centrada na racionalidade técnica. No entanto, os depoimentos coletados nesta pesquisa confirmam que essa lógica é utilizada como modelo básico para a ação docente, pois, provavelmente, esta foi a racionalidade vivenciada na formação inicial de muitos dos professores do ensino superior.

Por entender que esse desafio é potencializado quando tais docentes se encontram no início da carreira e que os momentos de formação continuada podem auxiliar nesse processo de constituição do ser professor, o presente trabalho buscou investigar as contribuições percebidas por professores universitários no seu processo de inserção em relação à formação continuada oferecida pela IES na qual atuam como docentes.

A intenção de desenvolver um estudo inicial sobre essa questão ocorreu com três movimentos. No primeiro, foi realizada a caracterização do processo de inserção na carreira docente universitária, indicando que este envolve a perspectiva do desenvolvimento profissional dos professores e que se configura como uma fase peculiar em que acontece a transição de estudante/pesquisador para docente. 
No segundo movimento foi feita uma discussão teórica, ainda que não exaustiva, a respeito da formação continuada de professores no ensino superior, demarcando a insuficiência de práticas formativas e de orientações legais que visam garantir a realização efetiva dessa formação na perspectiva da educação superior. Com efeito, trata-se de ir além de uma mera preparação para a docência para envolver os aspectos institucionais, os relacionados à pesquisa e ao contexto da educação superior, favorecendo refletir também sobre as finalidades da universidade.

O terceiro foi direcionado a identificar as contribuições da formação continuada para o início da carreira docente universitária com a análise das percepções de professores que estão na fase de desenvolvimento profissional. Os dados coletados possibilitaram concluir de forma preliminar que a maioria dos professores investigados percebem que os momentos de formação continuada contribuem principalmente nos aspectos relacionados ao saber fazer didático, incluindo, então, as questões pedagógicas da ação docente em sala de aula. Ainda, a pesquisa aponta indícios de que na maioria das instituições não há programa de formação e de apoio para os professores iniciantes. As dificuldades desses docentes abrangem questões relacionadas ao ensino, mas as dúvidas e incertezas são amplas. Desse modo, seria recomendável a oferta de programa específico de inserção à docência.

E em especial, cabe ressaltar que o desafio da docência exige uma mudança profunda na compreensão das finalidades da educação superior para além de um ensino centralizado na transmissão e reprodução de informações, situações pouco abordadas na formação continuada. A perspectiva de uma pedagogia universitária poderá orientar os programas de formação, incluindo a criação de condições de participação para todos os docentes. 


\section{REFERÊNCIAS}

1. BAPTAGLIN, Leila Adriana; ROSSETTO, Gislaine Aparecida Rodrigues da Silva; BOLZAN, Doris Pires Vargas. Professores em formação continuada: narrativas da atividade docente de estudo e a da aprendizagem da docência. Educação (UFSM). Santa Maria, ago. 2014, vol.39, n.2, p. 415-426. e-ISSN: 1984-6444. Disponível em: https://periodicos.ufsm.br/reveducacao/article/view/6428/pdf. Acesso em: 10 jul. 2017. DOI: http://dx.doi.org/10.5902/198464446428.

2. BRASIL. Lei 9394, de 20 de dezembro de 1996. Estabelece as diretrizes e bases da educação nacional. Brasília, 1996. Disponível em: http://www.planalto.gov.br/ccivil_03/leis/L9394.htm. Acesso em: 25 abr. 2017.

3. CUNHA, Maria Isabel da (Org.). Reflexões e práticas em pedagogia universitária. Campinas: Papirus, 2007.

4. CUNHA, Maria Isabel da. Os desafios da qualidade acadêmica e a indissociabilidade do ensino, pesquisa e extensão num contexto de democratização da educação superior. Intercambios: Dilemas y Transiciones de la Educación Superior, v. 1, p. 13-21, 2014. Disponível em: https://dialnet.unirioja.es/servlet/articulo?codigo=5436842. Acesso em: 20 nov. 2018.

5. CUNHA, Maria Isabel da. Inovações em educação superior: impactos na prática pedagógica e nos saberes da docência. Em Aberto, v. 29, p. 87-101, 2016. Disponível em: http://emaberto.inep.gov.br/index.php/emaberto/article/view/2955. Acesso em: 10 ago. 2019. DOI: http://dx.doi.org/10.24109/2176-6673.emaberto.29i97 .

6. CUNHA, Maria Isabel da. Docência na Educação Superior: a professoralidade em construção. Educação. Porto Alegre, jan./abr. 2018, vol. 41, n.1, p. 6-11. Disponível em: http://revistaseletronicas.pucrs.br/ojs/index.php/faced/article/view/29725. Acesso em: 21 nov. 2018. DOI: http://dx.doi.org/10.15448/1981-2582.2018.1.29725.

7. DAY, Christofer. Compreender o desenvolvimento profissional dos professores: experiência, saberfazer profissional e competência. In: DAY, Christofer. Desenvolvimento profissional dos professores: os desafios da aprendizagem permanente. Portugal: Porto Editora, 2001. p. 85-114.

8. GIBBS, Graham. Análise de dados qualitativos. Porto Alegre: ArtMed, 2009.

9. HUBERMAN, Michel. O ciclo de vida profissional dos professores. In: NÓVOA, Antonio (Org.). Vidas de professores. Porto/Portugal: Porto Editora, 1992. p. 31-61. 
10. ISAIA, Silvia Maria de Aguiar; BOLZAN, Dóris Pires Vargas; GIORDANI, Estela Maris. Movimentos construtivos da docência superior: delineando possíveis ciclos de vida profissional docente. In: REUNIÃO ANUAL DA ANPED, 30., 2007, Caxambu. Anais eletrônicos. Caxambu: ANPEd, 2007, p. 01-14. Disponível em: http://30reuniao.anped.org.br/trabalhos/GT08-3213--Int.pdf. Acesso em: 10 jul. 2017.

LACEY, Colin. The socialization of teachers. London: Metheun, 1977.

12. LÜDKE, Menga; ANDRÉ, Marli E. D. A. Pesquisa em educação: abordagens qualitativas. 2 ed. São Paulo: EPU, 2013.

13. MARCELO GARCÍA, Carlos. Formação de professores: para uma mudança educativa. Porto/Portugal: Porto Editora, 1999.

14. MARCELO GARCÍA, Carlos. O professor iniciante, a prática pedagógica e o sentido da experiência. Formação Docente: Revista Brasileira de Pesquisa sobre Formação de Professores. ago./dez. 2010. vol. 2, n.3, p. 11-49. e-ISSN: 2176-4360. Disponível em: https://revformacaodocente.com.br/index.php/rbpfp/article/view/17. Acesso em: 21 nov. 2018.

15. MOROSINI, Marília Costa. Docência universitária e os desafios da realidade nacional. In: MOROSINI, Marília Costa (Org.). Professor do ensino superior: identidade, docência e formação. 2.ed. ampl. Brasília: Plano Editora, 2001.

PIMENTA, Selma Garrido; ANASTASIOU, Léa das Graças Camargos. Docência no Ensino Superior. 5. ed. São Paulo: Cortez, 2014.

17. PIMENTA, Selma Garrido; ALMEIDA, Maria Isabel. Pedagogia Universitária: caminhos para a formação de professores. São Paulo: Cortez, 2011.

18. ROMANOWSKI, Joana Paulin. Formação continuada. In: ROMANOWSKI, Joana Paulin. Formação e profissionalização docente. 3. ed. rev. e atual. Curitiba: Ibpex, 2007. p. 130-163.

19. ROMANOWSKI, Joana Paulin; MIRA, Marilia Marques. Condições de inserção profissional do professor da educação superior. In: WIEBUSCH, Eloisa Maria; VITÓRIA, Maria Inês Côrte. (Org.). Estreantes no ofício de ensinar na educação superior. Porto Alegre: EdiPUCRS, 2018. p. 99-120.

20. VAILLANT, Denise; MARCELO, Carlos. Ensinando a ensinar: as quatro etapas de uma aprendizagem. Curitiba: Ed. UTFPR, 2012. 
21. VEIGA, IIma Passos Alencastro. Docência universitária na educação superior. In: RISTOFF, Dilvo; SEVEGNANI, Palmira. (Org.). Docência na Educação Superior. Brasília: Instituto Nacional de Estudos e Pesquisas Anísio Teixeira, 2006. (Coleção Educação Superior em Debate; v.5).

22. VEIGA, Ilma Passos Alencastro; CASTANHO, Maria Eugênia. L. M. (Orgs.). Pedagogia Universitária: a aula em foco. Campinas, São Paulo: Papirus, 2000.

23. VEIGA, Ilma Passos Alencastro. Educação superior: políticas educacionais, currículo e docência. Curitiba: CRV, 2016.

24. ZANCHET, Beatriz Maria B. Atrib. et al. Tempos e espaços de inserção e desenvolvimento profissional de docentes universitários iniciantes. In: CUNHA, Maria Isabel da. (Org.). Estratégias institucionais para o desenvolvimento profissional docente $\mathrm{e}$ as assessorias pedagógicas universitárias: memórias, experiências, desafio e possibilidade. Araraquara, São Paulo: Junqueira \& Marin editores, 2014. p. 187-213.

\section{Priscila Ximenes Souza do Nascimento}

Doutoranda do Programa de Pós-Graduação em Educação - PUCPR. Mestra em Educação - UFPE; Professora do Curso de Pedagogia - PUCPR.

\section{Joana Paulin Romanowski}

Doutora em Educação - USP, Professora do Programa de Pós-Graduação em Educação - UNINTER e PUCPR.

\section{Como citar este documento}

NASCIMENTO, Priscila Ximenes Souza do; ROMANOWSKI, Joana Paulin. Contribuições da formação continuada para professores universitários ingressantes. Reflexão e Ação, Santa Cruz do Sul, v. 28, n. 1, Jan. 2020.2 ISSN 1982-9949. Disponível em: <https://online.unisc.br/seer/index.php/reflex/article/view/13022>. Acesso doi:https://doi.org/10.17058/rea.v28i1.13022. 